\title{
O organismo como referência fundamental para a compreensão do desenvolvimento cognitivo
}

\section{The organism as fundamental reference for the comprehension of the cognitive development}

Barros, Carlos Eduardo ${ }^{1}$, Carvalho, Maria Imaculada Merlin", Gonçalves, Vanda Maria Gimenes², Ciasca, Sylvia Maria², Mantovani de Assis, Orly Zucatto³.

\section{RESUMO}

O objetivo deste estudo é estabelecer uma aproximação dos conceitos piagetianos com os avanços da neurociência, visando ratificar a compreensão do processo de construção das estruturas mentais. Pesquisadores interessados na função do cérebro têm tido oportunidade sem precedentes de examinar a correlação neurobiológica do comportamento humano, contribuindo significativamente para o desenvolvimento da neurociência cognitiva, um campo de pesquisa que combina as estratégias experimentais da psicologia com várias técnicas que examinam como a função cerebral sustenta a atividade mental. Conceituando a inteligência como um prolongamento da adaptação biológica do organismo ao meio e tendo sido evidenciado pela filogênese a ação precedendo a progressiva corticalização de funções, enfatiza-se o desenvolvimento cognitivo como um processo, no qual as atividades do sujeito possibilitam as trocas com o meio de uma forma dinâmica, do nível de organização biológica e neurológica até o cognitivo. Assim, a proposta deste trabalho é refletir sobre o modelo neurobiológico atual e as interpretações comuns com a psicologia genética. Neste artigo serão estudadas algumas aproximações entre estes dois ramos do conhecimento humano, porém, considerando a diferença temporal de mais de 50 anos entre ambas teorias.

Unitermos: Psicologia genética, Neurodesenvolvimento, Inteligência, Mente.

\section{SUMMARY}

The purpose of this study is to approach the Jean Piaget's concepts and the advances in neurosciences, in order to ratify the process in the construction of the mental structures. Researchers interested in the function of the human brain were presented with an unprecedented opportunity to

Trabalho realizado:Universidade Estadual de Campinas/Campinas/São Paulo

1 - Pós-graduando, Curso de Pós-graduação em Ciências Médicas.

2 - Professora Livre Docente, Departamento de Neurologia, Faculdade de Ciências Médicas e do Centro de Investigação em Pediatria (CIPED).

3 - Professora Assistente Doutora, Faculdade de Educação e Laboratório de Psicologia Genética.

- Membros do Grupo de Pesquisa: Neurodesenvolvimento, Escolaridade e Aprendizagem, registrado no CNPq e certificado pela instituição de origem. 
examine the neurobiological correlation of human behavior and they contributed significantly to the development of the field of cognitive neuroscience, a field of research that combines the experimental strategies of psychology with techniques to actually examine how brain function supports mental activities. The concept of intelligence as an extension of biological adaptation of the human body to the environment confirms what we have known all along, and the action preceding the progressive corticalization of functions has been evidenced. We emphasize the comprehension of the cognitive development as a process in which the man's activity makes the exchange with the environment in a dynamic way, from the biological and neurological organization until the cognitive level. So, our objective is to think about a current neurobiological model and to compare with concepts of the genetic psychology. In this paper will be studied some interaction between the two areas, considering that it has been nearly 50 years between both.

Keywords: Genetic psychology, Neurodevelopment, Intelligence, Mind.

\section{INTRODUÇÃO}

Ao se contemplar o panorama atual das ciências que buscam explicar o homem, identifica-se a interseção de suas fronteiras. Os limites rígidos de seus objetos e métodos são agora transpostos. Para se compreender o fenômeno humano nenhuma ciência basta por si, não obstante todas serem necessárias. Como ilustra Omnès ${ }^{1}$ as raízes comuns da realidade não respeitam os sítios definidos de nossas preferências. As resistências do real obrigam a modificar posições, porquanto ele não se reduz à maneira como se prefere olhar, mas exige que a pesquisa coordene várias abordagens científicas para explicá-lo ou pelo menos para construir um modelo mais próximo da realidade. Assim, várias ciências se uniram a partir da década de 80 do século passado constituindo as neurociências².

Pesquisadores interessados na função do cérebro tem tido novas oportunidades sem precedentes de examinar a correlação neurobiológica do comportamento humano, contribuindo significativamente para o desenvolvimento da neurociência cognitiva, um campo de pesquisa que combina as estratégias experimentais da psicologia com várias técnicas que examinam como a função cerebral sustenta as atividades mentais ${ }^{3}$. A neurociência cognitiva aborda temas de importância como, por exemplo, os aspectos de normalidade e de alteração de memória, atenção, linguagem, motivação, emoção e consciência.
Apesar dos avanços, alguns pesquisadores têm questionado a habilidade desta abordagem em analisar a função cerebral, se as mesmas são suficientemente refinadas para verdadeiramente esclarecer sobre a relação entre comportamento humano e função cerebral ${ }^{4}$.

Um ponto chave para avaliar tal preocupação é a habilidade de relacionar os trabalhos em neurociência cognitiva e neuroimagem com aqueles em outras áreas de neurociências. Entre as questões mais importantes está como relacionar a neuroimagem funcional com a biologia celular e neurofisiologia das células cerebrais e sua microvasculatura. Além disso, tem sido questionado se a neurociência cognitiva e os instrumentos da neuroimagem têm oferecido nova compreensão sobre a função e organização cerebral, ou apenas tem confirmado o que já era conhecido ${ }^{3}$.

Gonçalves ${ }^{5}$ refere que um dos objetivos da neurociência cognitiva é relacionar o período do desenvolvimento cognitivo com o desenvolvimento neural para elucidar a neurobiologia da cognição. Discussões sobre o desenvolvimento neurocognitivo foram por muito tempo dominados e abafados pelo debate nature-nurture. Atualmente, a maioria dos investigadores valoriza ambos: o papel do controle biológico imposto pelo genótipo e o papel da informação ambiental na expressão gênica e outros eventos químicos e fisiológicos do desenvolvimento. O desenvolvimento neurocognitivo depende da interface dinâmica e complexa entre eventos genéticos predetermi- 
nados e eventos ambientais. O grau de interface é altamente variável nos diferentes sistemas neurocognitivos, conduzindo a diferentes graus e adequação de tempo de sensitividade às aferências ambientais, para as diferentes funções cerebrais.

Conforme Mesulam, a informação sensorial passa por elaboração associativa extensa e modulação atencional na medida em que se torna incorporada à cognição ${ }^{6}$. Esse processo ocorre ao longo de um núcleo sináptico hierárquico que inclui o córtex cerebral sensorial primário, zonas unimodais, zonas heteromodais, áreas límbica e paralímbica. A organização sináptica resultante permite que cada evento sensorial inicie resultados múltiplos cognitivos e comportamentais. A tarefa maior do sistema nervoso é configurar a maneira como a informação sensorial se torna vinculada a respostas adaptativas e experiências significativas.

Do ponto de vista cognitivo, novas estruturas estão se construindo nos diferentes estágios de desenvolvimento como uma resposta do organismo às estimulações ou solicitações do meio. A partir da interação fundamental entre o sujeito e o meio desencadeiam-se as assimilações e acomodações que terminam em equilibrações que tendem à conservação das estruturas, mas produzem também suas modificações?

Essas colocações introduzem a complexidade do que seja compreender o homem a partir de uma perspectiva multifacetada: da neurobiologia à psicologia cognitiva. É uma busca que requer a cooperação interdisciplinar.

Ponderando esses aspectos, encontrou-se no modelo neurobiológico atual sobre a mente interpretações comuns com a psicologia genética, na medida que tenta explicá-la como resultado da interação corpo-cérebro. Neste artigo serão estudadas algumas aproximações entre estes dois ramos do conhecimento humano, porém, com uma diferença temporal de mais de 50 anos.

O epistemólogo e psicólogo Jean Piaget, preocupado em elaborar uma teoria do conhecimento, questionou a origem sensorial do conhecimento científico ${ }^{8}$. Origem que desde Aristóteles até nossos dias tem sido aceita sem questionamentos mais profundos. Parece tão evidente que apenas os sentidos dão conta de toda a significação do mundo, que não nos ocorre hipotetizar a necessidade de sua participação, mas de maneira não suficiente na elaboração do conhecimento. Na verdade, esta questão compõe uma outra que tem sido discutida ao longo dos séculos por filósofos e cientistas: a natureza objetiva dos sistemas explicativos. O conhecimento da física será uma cópia do real? As explicações em biologia reproduzem a realidade da vida? Vários pensadores ora se posicionaram de acordo com o empirismo com nuances próprios, ora de acordo com o racionalismo que coloca o homem como a medida do mundo.

Tentativas inúmeras de superação dessas oposições foram feitas até encontrar hoje vasto panorama epistemológico, nos vários ramos da ciência que explicam que o homem, pela própria natureza e funcionamento dos sentidos, constrói representações aproximativas da realidade, o denominado conhecimento. Na medida em que a pesquisa avançou para o infinitamente pequeno, os átomos, e para o infinitamente distante, a origem do universo, buscou-se modelo explicativo construído pela imaginação humana que se distanciou dos dados perceptivos. Procurou-se, por trás dos efeitos, remontar ao funcionamento da realidade não perceptível em sua causalidade. Pouco a pouco a matemática libertou-se do mundo, dando-se conta de que estava tratando de relações puras, independentes de qualquer conteúdo específico. A evolução dos modelos atômicos mostrou bem o esforço aproximativo da realidade atual, sem, contudo, alçar-se à pretensão de apresentar a realidade em si mesma.

O avanço no estudo do sistema visual humano mostrou que não se tem fotografia da realidade no cérebro, mas representações no lobo occipital que se construíram a partir das transduções analógicas e digitais ao longo do trajeto subcortical e cortical da imagem visual ${ }^{9}$. Emoção, humor e motivação modulam o impacto neural dos eventos sensoriais de uma maneira que reflete o valor subjetivo desses eventos para o indivíduo ${ }^{6}$.

Esta questão foi discutida por outro grande autor e neurologista. Damásio referiu serem os sentimentos a representação mental de alterações fisiológicas que caracterizam as emoções ${ }^{10}$. 0 principal alvo da resposta emocional é o corpo: 
meio interno, vísceras e sistema músculoesquelético, mas há também alvos dentro do cérebro, como os núcleos monoaminérgicos no tegmento do tronco encefálico. O resultado da resposta do corpo é a criação de um estado emocional, envolvendo ajustes no balanço homeostático. O resultado das respostas do cérebro é uma alteração no modo de operação cerebral durante os ajustes emocionais do corpo, cuja conseqüência é, por exemplo, a mudança na atenção direcionada para o estimulo.

Damásio também apresentou um modelo plausível para a mente humana, esboçando uma explicação neurobiológica ${ }^{11}$. Apresentou a idéia de que o organismo como um todo é necessário para explicar o pensamento. Alegou que o corpo proporciona uma referência fundamental para a mente, retomando o problema da percepção que a seu ver não se reduz a receber informações sensoriais, mas evoca a ação do organismo sobre o meio ambiente.

Outro aspecto relevante faz convergir às ponderações de Piaget e Damásio, autores de áreas diferentes e em tempos diferentes: não é apenas a natureza biológica desta questão, mas a compreensão da função adaptativa da mente e da inteligência. Em realidade, é esta proposição que faz com que haja tanta identidade entre suas explicações. Superando a dicotomia cartesiana pensamento versus corpo, cada um estabelece a seu modo e em seu campo específico, um contínuo corpo-mente no qual se encontram extremos que se tocam por uma indiferenciação gradativa. Essas duas realidades não se justapõem, mas a primeira é referência para a outra sem que a última a ela se reduza. Este contínuo é um prolongamento de formas adaptativas tanto quanto os sentidos se desenvolvem e aperfeiçoam para aprimorar a ação.

Piaget descreveu a inteligência como o estado de equilíbrio para o qual tendem todas as estruturas cognitivas e não como uma faculdade ${ }^{12}$. Opinião semelhante foi referida por David Weschler ${ }^{13}$. Este a considerava como "um efeito, mais do que uma causa, isto é, um resultado de capacidades que se interagem, inclusive as não intelectivas".

Damásio propôs um modelo interacionista para explicar a existência da mente ${ }^{11}$. Acreditou que o corpo é uma referência básica para o cérebro construir suas representações adaptativas. Assim, observa-se em Damásio a retomada da questão piagetiana de entender as funções mentais, a própria inteligência como um prolongamento de formas adaptativas do organismo.

Pouco a pouco a visão fragmentada do psíquico vai sendo substituída nas ciências do homem pela visão estruturalista ${ }^{14}$, que apontou a coordenação de ações como condição de aprendizado. Esse aspecto se reflete na coordenação de sistemas de Luria nas unidades funcionais ${ }^{15}$, nos neurofisiologistas que descobriram áreas de sensação, associação e integração ${ }^{16}$.

A inteligência não está definida no início, mas é um ponto de chegada graças às trocas e atualizações que o organismo estabelece com o meio. O conhecimento, na visão de Damásio, confirmando Piaget, não pode ser visto como produto dos sentidos e não está definido no genoma; tem por base as ações do organismo que são representadas por duas vias: o sentir e o sentir que está sentindo. Há interação dos mapas somatosensoriais e motores numa representação e integração continuadas. Pode-se supor que uma informação já representada é assimilada repetidamente sem alteração dos mapas e acomodada quando se diferencia.

Desde os estudos evolucionistas, compreender as possibilidades da espécie não dispensa a comparação da ontogênese e da filogênese ${ }^{17}$. As aquisições estruturais e funcionais ganharam nova compreensão com os estudos etológicos. Das descrições embriológicas históricas de Von Baer comparando as etapas estruturais dos fetos ao estudo longitudinal da inteligência humana, a adaptabilidade dos organismos se complexifica utilizando recursos cada vez mais sofisticados: da especialização sensorial às elaborações complexas da razão humana ${ }^{18}$.

Piaget propôs que a ação inteira e não a sensação nem a percepção isoladas originam os nossos conhecimentos científicos. A ação, para este autor, é central para a compreensão da inteligência em seu caráter operatório e transformador. O conhecimento não se reduz a vivência, o que seria empirismo, e nem somente explicação, o que seria racionalismo, mas a uma estruturação do vivido no qual o caráter 
transformador da ação possibilita assimilar o real às estruturas prévias ${ }^{19}$. No seu livro Psicologia e Epistemologia, Piaget traduz suas hipóteses da seguinte forma ${ }^{8}$ :

Os nossos conhecimentos não provêm nem da sensação nem da percepção isolada, mas da ação inteira da qual a percepção constitui somente a função de sinalização. O próprio da inteligência não é, com efeito, contemplar, mas "transformar", e o seu mecanismo é essencialmente operatório. Ora, as operações consistem em ações interiorizadas e coordenadas em estruturas de conjunto (reversíveis, etc), e se quer dar conta deste aspecto operatório da inteligência humana, é, pois, da própria ação, e não apenas da percepção, que convém partir.

Os processos de assimilação orgânicos fornecem a visão de quanto à incorporação de elementos do ambiente supõe a intensa atividade do organismo. O simples fato de a alimentação requerer um conjunto de ações orgânicas para a digestão e somente posterior integração dos elementos à estrutura do organismo, mostra o quanto é simplista a visão de internalização do meio social e ambiental, que não considere a atividade transformadora do indivíduo.

A concepção da inteligência como fenômeno evolutivo adaptativo implica a existência de mecanismos funcionais assimilativos tanto quanto os outros sistemas orgânicos. Segundo Piaget a inteligência transforma o mundo modificando-o de duas maneiras ${ }^{8}$ :

- Modificando as posições, o movimento ou a natureza do objeto do conhecimento para the explorar a natureza;

- Enriquecendo-o com propriedades ou relações novas que conservam as suas propriedades ou relações anteriores, mas que as completam através de sistemas de classificações, ordenações, estabelecimentos de correspondência, enumerações ou medidas, etc.

São essas duas maneiras de agir sobre o mundo, respectivamente ação física e ação lógicomatemática, que a par da percepção constituem as fontes dos conhecimentos científicos. A ação naturalmente precede a encefalização tanto ontogeneticamente quanto na filogênese.
REFERÊNCIAS BIBLIOGRÁFICAS

1. Omnès R. Filosofia da ciência contemporânea. Tradução de Roberto Lea Ferreira. São Paulo: Editora UNESP, 1996.

2. Lent R. Cem bilhões de neurônios: conceitos fundamentais de neurociência. São Paulo: Editora Atheneu, 2001

3. Marcus ER. Functional brain imaging and human brain function. J Neurosci 2003; 23: 3959-3962.

4. Nichols MJ, Newsome WT (1999). The neurobiology of cognition. Nature 1999; 402: C35-C38.

5. Gonçalves VMG. Neurodesenvolvimento e indicadores de risco: do neonato ao escolar. Campinas, 2003. (Tese de Livre-Docência), Universidade Estadual de Campinas.

6. Mesulam M-M. From sensation to cognition. Brain 1998; 121: 1013-1052.

7. Mantovani de Assis OZM. A solicitação do meio e a construção das estruturas lógicas elementares na criança. Campinas, 1976. (Tese de Doutorado), Universidade Estadual de Campinas.

8. Piaget J. Psicologia e Epistemologia. Para uma teoria do conhecimento. Tradução de Maria de Fátima Bastos. Lisboa: Publicações Dom Quixote, 1991.

9. Kandel ER, Schwartz JH, Jessel TM. Principles of neural science. New York: International Edition Mc Graw Hill, 2000.

10. Damasio A. Fundamental feelings. Nature 2001; 413: 781
11. Damásio AR. O erro de Descartes: emoção, razão e o cérebro humano. Tradução portuguesa Dora Vicente e Georgina Segurado. São Paulo: Companhia das Letras, 1996

12. Piaget J. Psicologia da Inteligência. Tradução de Egléa de Alencar. Brasil Portugal: Editora Fundo de Cultura, 1967.

13. Matarazzo J. Weschler - medida e avaliação da inteligência do adulto. São Paulo: Manole, 1976.

14. Piaget J. O Estruturalismo. São Paulo: Editora Difel, 1979.

15. Luria AR. Fundamentos de neuropsicologia. São Paulo: Edusp/Livros Técnicos e Científicos, 1981

16. Damasceno BP, Guerreiro MM. Desenvolvimento neuropsíquico: suas raízes biológicas e sociais. Cadernos CEDES 2000; 24: 13-20.

17. Fonseca V. Manual de observação psicomotora: significação psiconeurológica dos fatores psicomotores. Porto Alegre: Artes Médicas, 1995.

18. Gilbert SF. Biologia do desenvolvimento. Tradução de Márcia Maria Gentile Bitondi e Zilá Luz Paulino Simões. Ribeirão Preto: Sociedade Brasileira de Genética, 1994.

19. Ramozzi-Chiarottino Z. Psicologia e Epistemologia Genética de Jean Piaget. São Paulo: EPU, 1988 